\title{
Adsorption-induced pore blocking and its mechanisms in nanoporous shale due to interactions with supercritical $\mathrm{CO}_{2}$
}

\author{
Xianfu Huang ${ }^{\mathrm{a}, \mathrm{b}}$, Ya-Pu Zhao ${ }^{\mathrm{a}, \mathrm{b}, *}$, Xiaohe Wang $^{\mathrm{a}, \mathrm{b}}$, Lisheng Pan ${ }^{\mathrm{c}}$ \\ ${ }^{a}$ State Key Laboratory of Nonlinear Mechanics, Institute of Mechanics, Chinese Academy of Sciences, Beijing 100190, People's Republic of China \\ ${ }^{\mathrm{b}}$ School of Engineering Science, University of Chinese Academy of Sciences, Beijing 100049, People's Republic of China \\ ${ }^{\mathrm{c}}$ State Key Laboratory of High Temperature Gas Dynamics, Institute of Mechanics, Chinese Academy of Sciences, Beijing 100190, People's Republic of China
}

\section{A R T I C L E I N F O}

\section{Keywords:}

Shale oil and gas

$\mathrm{CO}_{2}$ sequestration

Swelling

Chemical reaction

Nitrogen adsorption isotherm

XPS

\begin{abstract}
A B S T R A C T
Supercritical carbon dioxide $\left(\mathrm{sCO}_{2}\right)$ has recently been used to recover hydrocarbons from shale formations due to its advantages in boosting production, saving water, and minimizing environmental impacts. $\mathrm{Meanwhile}, \mathrm{CO}_{2}$ is sealed up underground, which would cut down the greenhouse gas emissions and reduce global warming. However, current knowledge regarding how $\mathrm{sCO}_{2}$ interacts with shale, especially its nanopores which are responsible for adsorption, migration and storage of oil and gas, has been lacking. Here we show that after $\mathrm{sCO}_{2}$ adsorption, the total pore volume decreases by $\sim 20 \%$ in nanoporous shale, majorly by up to $60 \%$ in the range of $0.85-2.0 \mathrm{~nm}$. We analyze the morphology and composition changes in shale, and show that the nanopore is either closed up or newly opened, with more closed pores than new ones. We for the first time propose that this adsorption-induced pore blocking phenomenon is jointly voluminal and geochemical resulted from physisorption, associative chemisorption and dissociative chemisorption of $\mathrm{sCO}_{2}$ in shale. Our results help to effectively assess the hydrocarbon production capacity in shale gas reservoirs using $\mathrm{CO}_{2}$-fracking technique, and the $\mathrm{CO}_{2}$ storage potential in shale formations.
\end{abstract}

\section{Introduction}

In recent years, hydrocarbon production from organic-rich shales, also known as shale oil and gas (Hughes, 2013; Kerr, 2010), has been exploded for economic and environmental purposes-it releases vast amounts of energy previously inaccessible, reduces the reliance on energy imports, and cuts down the carbon dioxide $\left(\mathrm{CO}_{2}\right)$ emissions. It is all due to the recent technological developments in horizontal drilling and hydraulic fracturing. Hydraulic fracturing, also called fracking or hydrofracturing, is a well stimulation technique that creates cracks in deep-rock formations by injecting pressurized liquid into cracks to force them open and keep thereafter (Howarth et al., 2011; Shen and Zhao, 2017). The injected liquid is a mixture of water, sand and small amount of chemicals (Stringfellow et al., 2014). This brings about the concern over the possible adverse implications such as water scarcity and contamination, health risks on humans, and triggering earthquakes, etc. (Ellsworth, 2013; Jackson et al., 2013; Osborn et al., 2011; Vengosh et al., 2014; Vidic et al., 2013). Scientists are looking for 'green fracking' technique, that is, using supercritical carbon dioxide $\left(\mathrm{sCO}_{2}\right)$ as an alternative to water for fracking (Middleton et al., 2015). Supercritical $\mathrm{CO}_{2}$ is a fluid state where it is held at or above its critical temperature and critical pressure, which behaves low viscosity and high diffusivity. This waterless strategy creates a better fracture network, conquers the 'energy barriers' at a microscopic level, (Lee et al., 2016), and frees the hydrocarbon from the nanoporous shale and thus enhances the recovery (Lin et al., 2016). More importantly, the $\mathrm{CO}_{2}$ is stored underground after the exploiting time (Edwards et al., 2015; Farajzadeh et al., 2007; Godec et al., 2013; Kang et al., 2011), raising hopes that reduce greenhouse gas emission and environmental footprint. This environmentally-friendly $\mathrm{CO}_{2}$-fracking technique has largescale economic and political consequences. Naturally, investigating the geochemical and geophysical process of $\mathrm{sCO}_{2}$ interacting with shale, especially the influences to its nanopores, is important for building models to enhance the effectiveness of hydrocarbon production and $\mathrm{CO}_{2}$ sequestration.

As shown in Fig. 1, when $\mathrm{sCO}_{2}$ is injected into the shale formations at high pressure, for one thing it fractures the rock. For another it displaces oil or gas molecules and adsorbs to the nanopores and natural fractures. Shale is organic-rich sedimentary rock, composed of nanoporous organic matter (kerogen [Bousige et al., 2016; Yang et al., 2017] and bitumen [Burnham et al., 2018]) scattered in a mineral framework (Huang and Zhao, 2017; Pomerantz, 2015), including tiny particles of

\footnotetext{
*Corresponding author. State Key Laboratory of Nonlinear Mechanics, Institute of Mechanics, Chinese Academy of Sciences, Beijing 100190, PR China.

E-mail address: yzhao@imech.ac.cn (Y.-P. Zhao).
} 


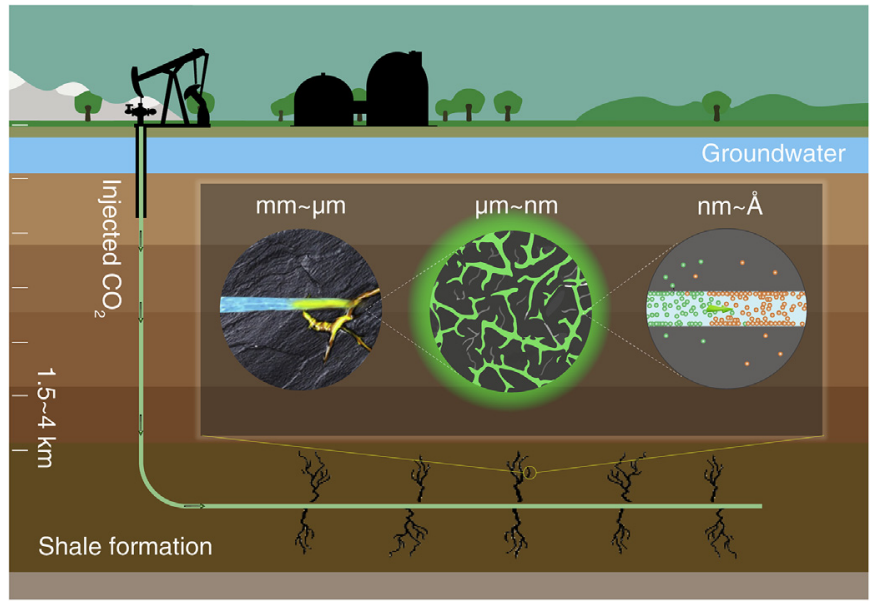

Fig. 1. Hydrocarbon recovery from shale formations using waterless $\mathrm{CO}_{2}$ fracking. Schematic illustration of a multiscale interaction of $\mathrm{sCO}_{2}$ (green) with nanoporous shale. First it creates a fracture network (black trees) in the shale formations (brown), which is better than water does. And then it flows into the microcracks and nanopores, displaces the oil and gas molecules (orange and blue) that stick to the shale. At last it adsorbs and diffuses in the pores and shale matrix (black and grey) due to its affinity for shale. When the well life ends, $\mathrm{CO}_{2}$ is sealed up underground, which will balance the formation pressure, cut down the greenhouse gas emissions and reduce global warming. (For interpretation of the references to colour in this figure legend, the reader is referred to the Web version of this article.)

clay $(<0.004 \mathrm{~mm}$ in size), quartz, mica, pyrite and calcite, etc. The heterogeneous solid organic matter is the source of hydrocarbons, which is characterized by low porosity with a feature pore size distribution ranging from a few $\AA$ to $\mu \mathrm{m}$ (Clarkson et al., 2013), and primarily at nanoscale. Theses ultra-fine nanopores are responsible for generation (Bousige et al., 2016), adsorption (Chen et al., 2017; Wu et al., 2015), transport (Falk et al., 2015; Phan et al., 2016; Yu et al., 2018), migration (Wood and Sanei, 2016) and storage (Zhong et al., 2016) of hydrocarbons during the geologic and production time. At a molecular scale, some recent works aimed at revealing the gas behavior in nanopores of shale matrix. Falk et al. (2015) demonstrated that Darcy's law fails to predict transport in nanoporous shale due to molecular adsorption. Monteiro et al., 2012 suggested a mathematical model of hydrocarbon flows in nanoscale size of pores and channels by introducing a strong pressure gradient that increases the permeability. Lee et al., 2016 revealed that hydrocarbon recovery is hampered at heterogeneous interface because of the interfacial effects of nanoporous media, also called the activated desorption phenomenon. They further emphasized that it is required to investigate the swelling effects as $\mathrm{CO}_{2}$ fracking, which may swell kerogen and reduce formation permeability. These changes will in turn impact the hydrocarbon production and $\mathrm{CO}_{2}$ storage.

Yet, despite its importance, our knowledge about how $\mathrm{sCO}_{2}$ interacts with shale sediment during the $\mathrm{CO}_{2}$-fracking is insufficient. From the literature review, it is found that the impact of carbon dioxide on rocks is still on debate due to the structural and geological complexities of the rock. As $\mathrm{CO}_{2}$ adsorbs to a porous medium, it decreases the surface energy of the adsorbent, resulting in a volumetric change known as swelling phenomena (Busch et al., 2016; Wang et al., 2015). Swelling of coal (Niu et al., 2017; Perera et al., 2013) and shale (Lu et al., 2016; Lyu et al., 2018) in $\mathrm{sCO}_{2}$ have been observed in experiments. The swelling phenomena at macroscale should be ascribed to microscopic change of adsorption energy. Apparently, if a bulk phase swells, it is intrinsically ascribed to the microstructure expansion. Examples have been found by Hanrahan et al., 2004 that the pore expands in mesoporous silicas during its swelling using $\mathrm{sCO}_{2}$, and by Jiang et al., 2016 that the porosity of shale increased with $\mathrm{sCO}_{2}$. Counterintuitively, however, completely opposite conclusions have been drawn that the pore volume decreases during the $\mathrm{sCO}_{2}$ exposure of shale (Zhou et al., 2017). Moreover, it has also been found that the coal swelling will change the reservoir permeability significantly (Pekot and Reeves, 2002). These unusual changes indicate the shrinking and blocking of pore structures in the rock, contrary to what is observed in the mesoporous silicas (Hanrahan et al., 2004).

In this study, we show that the total pore volume decreases by $\sim 20 \%$ and specific surface area (SSA) by up to $36 \%$ in shale after $\mathrm{sCO}_{2}$ adsorption. In particular, the volume of nanopores in the range of $0.85-2.0 \mathrm{~nm}$ declined sharply by up to $60 \%$. These nanoporosity reductions are a result of nanopore blocking induced by $\mathrm{sCO}_{2}$-water-minerals interactions, and is the root of 'swelling': The bulk shale swells, while the nanopore shrinks and blocks. Shale is an intrinsically complex material, both in its composition, pore structure and its size distribution. In geological conditions at high pressure and temperature, $\mathrm{sCO}_{2}$ reacts with tiny fragments of minerals or organics of shale, imposing an irreversible geochemical and morphological changes to the rock, that is, transforms the microstructures, and exert influences to the pore structures and their distributions. This new adsorption-induced pore blocking phenomenon is supported by the results of nitrogen adsorption @77 K, scanning electron microscopy (SEM) and X-ray photoelectron spectroscopy (XPS) observations. These changes can also explain why shale rock suffers a strength loss while a ductility improvement after adsorption of $\mathrm{sCO}_{2}$ (Lyu et al., 2018). The structural and mechanical changes are ascribed to the physisorption, associative chemisorption, and dissociative chemisorption of $\mathrm{sCO}_{2}$. As a practical implication of the present results, such decreases of pore volume and SSA will help us to assess the efficiency of hydrocarbon production using $\mathrm{CO}_{2}$-fracking, and as well the $\mathrm{CO}_{2}$ storage potential in shale formations.

\section{Materials and methods}

\subsection{Supercritical $\mathrm{CO}_{2}$ adsorption}

An organic-rich shale sample from Songliao Basin (NE China) was chosen because it holds representativeness of high organic matter contents, low maturity and abundant minerals. The shale sample was crushed to 50 mesh $(0.300 \mathrm{~mm})$ to enlarge acting surfaces, and was outgassed at $65^{\circ} \mathrm{C}$ for $6 \mathrm{~h}$ to remove previously adsorbed gases. Then the shale sample was divided into eight portions.

To explore how nanopores interact with $\mathrm{sCO}_{2}$, we designed a supercritical fluid platform and a sample cell to provide a stable pressure and temperature that above the critical values of $\mathrm{CO}_{2}$, as shown in Fig. 2.

When starting the $\mathrm{sCO}_{2}$ adsorption experiments, the sample cell was first filled with $\mathrm{CO}_{2}$. After that a portion of shale sample was placed into the cell. The cell was then sealed and immersion into the waterbath. Finally, we adjusted the reducing valve to provide the required pressure and the waterbath to the desired temperature. In our experiments, taking into account the actual geological conditions of the sample, the pressure was set to $11 \mathrm{MPa}$ and the temperature was $323.15 \mathrm{~K}\left(50^{\circ} \mathrm{C}\right)$, which is the supercritical condition of $\mathrm{CO}_{2}$, as illustrated in Fig. 3 the $\mathrm{CO}_{2}$ phase diagram. Seven portions of shale samples were placed in the cell one by one, and were adsorbed with $\mathrm{sCO}_{2}$ for seven different time periods, i.e., $0.5,2,4,6,10,16.5$ and $22 \mathrm{~h}$, respectively. Therefore, we obtained eight samples in all including the raw one that untreated with $\mathrm{sCO}_{2}$.

\subsection{Nitrogen adsorption-desorption measurement}

We tested the nitrogen adsorption isotherms of all the samples @ $77 \mathrm{~K}$ (eight in all including the raw sample that untreated with $\mathrm{sCO}_{2}$ ). The experiments were conducted on a surface area and porosimetry system (ASAP 2020 PLUS; Micromeritics, US). To remove the gases adsorbed to the pores, all the samples were outgassed at $65^{\circ} \mathrm{C}$ until 


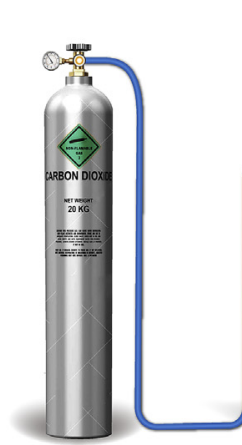

Gas cylinder

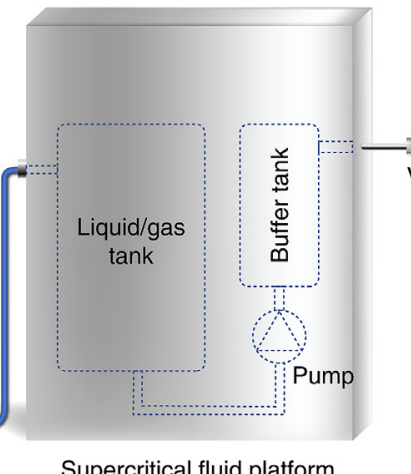

Supercritical fluid platform

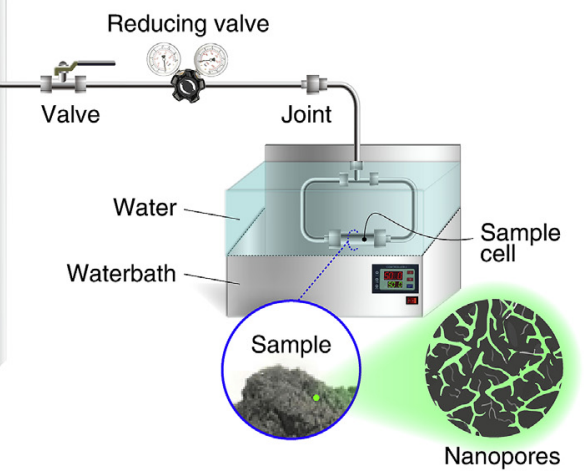

Fig. 2. The supercritical fluid platform which provides stable pressure and temperature conditions. In the experiments, the sample cell was first filled with $\mathrm{CO}_{2}$. After that a shale sample was placed into the cell. The cell was then sealed and immersion into the waterbath. Finally, the reducing valve is adjusted to provide a required pressure and the waterbath to a target temperature.

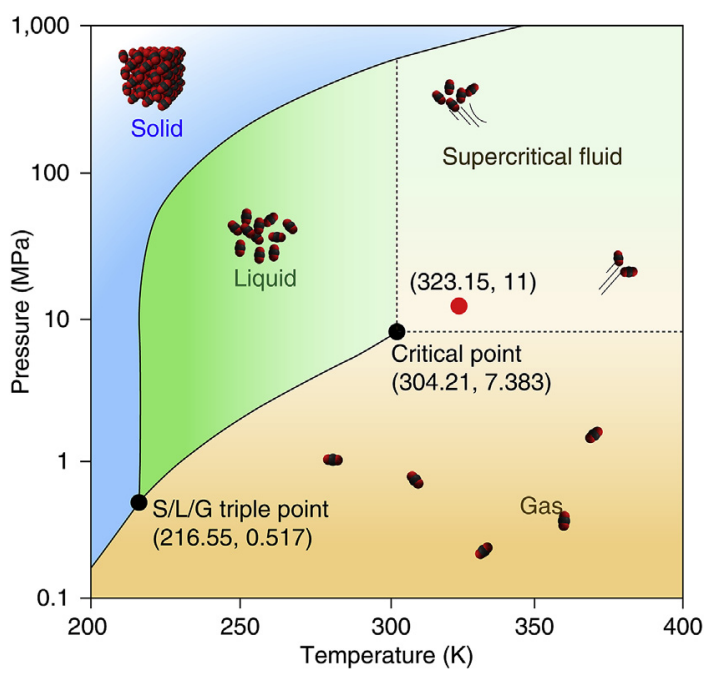

Fig. 3. Pressure-temperature phase diagram of $\mathrm{CO}_{2}$. The red point $(323.15 \mathrm{~K}$, $11 \mathrm{MPa}$ ) marked in the figure is the condition of the experiments conducted in this study. (For interpretation of the references to colour in this figure legend, the reader is referred to the Web version of this article.)

their masses remained unchanged. In our experiments, $6 \mathrm{~h}$ of evacuation and heating was a safe value for exhausting all the adsorbed gases. The gas used for the analysis was nitrogen. The analytical temperature was $77 \mathrm{~K}$ by immersing the sample tube in liquid nitrogen to provide a relative pressure range of 0.01-0.998 (Liu et al., 2019). Each sample was tested for three times. The specific surface area and the pore structure of the shale samples were analyzed based on the nitrogen adsorption-desorption measurement.

\subsection{SEM-EDS characterization}

To clarify the morphological changes in shale surface and pores after $\mathrm{sCO}_{2}$ adsorption, we used field emission SEM equipped with an energy dispersive spectrometer (EDS) to observe the shale samples before and after the adsorption. The surface morphology of shale was observed using a field emission SEM (FE-SEM, G300; Carl Zeiss, Germany) equipped with an EDS (Oxford Instruments, UK). The FESEM achieves nanometer-scale resolution and can visually observe the mineral structure and pore type morphology. Since the shale surface was not electrically conductive, it was sputtered with platinum (Pt) for $300 \mathrm{~s}$ before the observation. We observed the typical region of shale particles before and after $\mathrm{sCO}_{2}$ adsorption.

\subsection{XPS analysis}

To investigate the changes of minerals after $\mathrm{sCO}_{2}$ adsorption, we analyzed the eight shale samples by XPS and quantified the content of each substance using XPS-peak-differentiation-imitation analysis. The shale samples were first pressed into slice using a tablet press machine. Then their compositions and contents were tested on XPS (ESCALAB 250Xi; Thermo Fisher Scientific, US). The details of the measurements were: $\mathrm{Al} \mathrm{Ka}(1486.6 \mathrm{eV})$ excitation source, a scanning $\mathrm{Ar}^{+}$gun, a test area of $8 \times 8 \mathrm{~mm}^{2}$, a sputtering rate of $4 \mathrm{~nm} / \mathrm{min}$, an energy of $15 \mathrm{kV}$, and an emission current of $10 \mathrm{~mA}$. The XPS spectrums were analyzed by XPSPEAK 4.1 software. The functional groups of elements such as O, C, $\mathrm{Mg}, \mathrm{Si}, \mathrm{Al}, \mathrm{Fe}, \mathrm{Ca}$, and $\mathrm{K}$ were quantitatively analyzed.

\section{Results}

\subsection{Characteristics of nitrogen adsorption-desorption isotherms}

Fig. 4 shows the nitrogen adsorption-desorption isotherms of the eight shale samples. In the early stages, all the adsorption isotherms rose very slowly at low pressures $\left(p / p_{0} \leq 0.4\right)$, and appeared upward convex shapes, indicating that the adsorption transitions from the monolayer to the multimolecular layers (Liu et al., 2018). Then at intermediate pressures $\left(0.4<p / p_{0} \leq 0.8\right)$, the isotherms increased slowly with the increase of the relative pressure $p / p_{0}$, which is a multilayer adsorption process. At high pressures $\left(0.8<p / p_{0} \leq 1\right)$, the adsorption amount increased rapidly and did not exhibit any limiting adsorption, indicating that the large pores contained in the shale samples were filled due to capillary condensation. The relative pressures of capillary condensation and evaporation were different, which resulted in a hysteresis loop in the isotherms when $p / p_{0}<0.5$. As shown in Fig. 4, the desorption branch of the isotherms was above the adsorption branch, and differed among the shale samples, indicating that the pore structure of the samples has been changed after different adsorption time of $\mathrm{sCO}_{2}$. The lower closure point of adsorption and desorption branches occurred at a relative pressure of $\sim 0.42$. For the raw sample that untreated with $\mathrm{sCO}_{2}$, low pressure hysteresis was observed extending to the lowest attainable pressures. The reason may be that the irreversible uptake of gases in pores were close to the size of some adsorbate molecules.

According to the classification of adsorption isotherms and hysteresis recommended by the International Union of Pure and Applied Chemistry (IUPAC), all the isotherms were type IV and their loops were $\mathrm{H} 3$, indicating that the shale sample was primarily mesoporous material with a large number of parallel plate-like and slit-shaped pores (IUPAC classification of pores: Micropore: $<2.0 \mathrm{~nm}$; Mesopore: $2.0-50 \mathrm{~nm}$, Macropore: $>50 \mathrm{~nm}$ ) (Sing, 1985).

\subsection{Specific surface analysis}

To investigate the SSA varies, we applied the Brunauer-EmmettTeller (BET) theory (Brunauer et al., 1938), the most widely used 


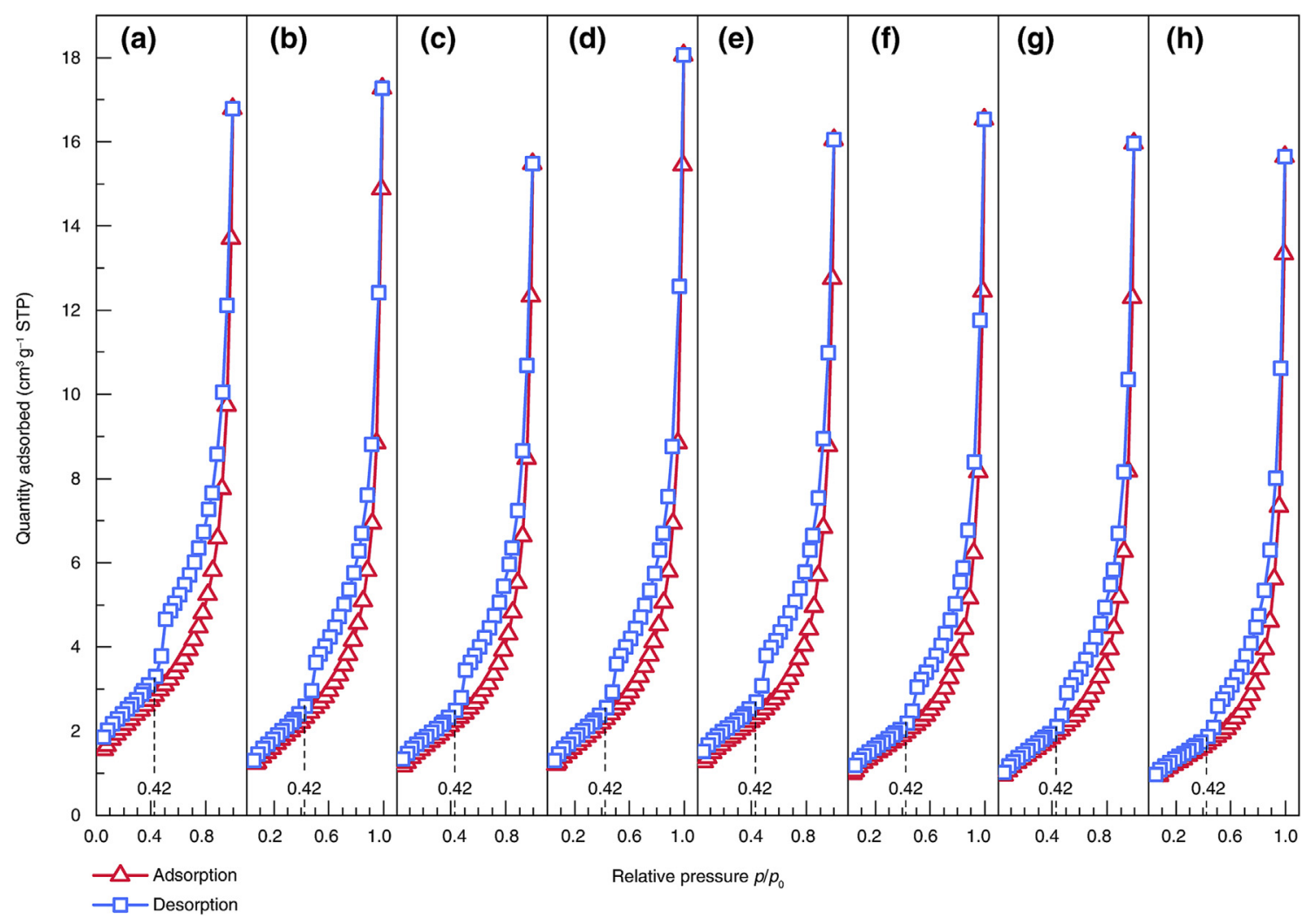

Fig. 4. Nitrogen adsorption-desorption isotherms of shale samples after different adsorption time of sCO 2 : (a) $0 \mathrm{~h}$; (b) $0.5 \mathrm{~h}$; (c) $2 \mathrm{~h}$; (d) $4 \mathrm{~h}$; (e) $6 \mathrm{~h}$; (f) $10 \mathrm{~h}$; (g) $16.5 \mathrm{~h}$; (h) $22 \mathrm{~h}$. The saturated vapor pressure $\left(p_{0}\right)$ is $103.5 \mathrm{kPa} @ 77 \mathrm{~K}$.

(a)

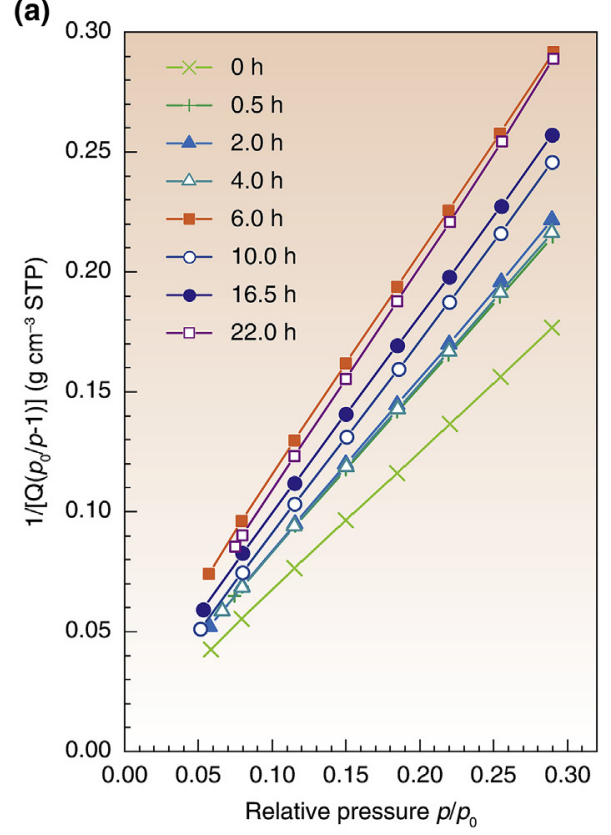

(b)

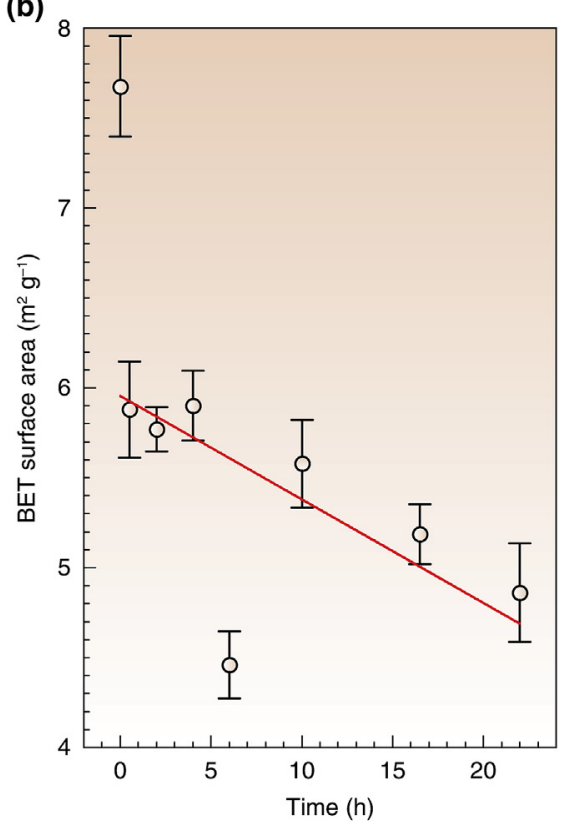

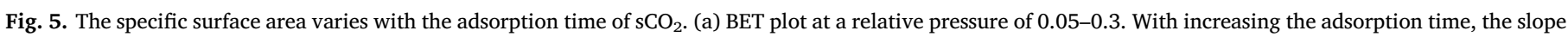
went up. (b) The calculated BET surface area. It decreased with adsorption time. After $22 \mathrm{~h}$ of $\mathrm{sCO}_{2}$ adsorption, the $\mathrm{SSA}$ decreased by up to $36 \%$.

method based on adsorption isotherm, to determine the specific surface area values of the samples. For mesoporous materials, the calculation of BET surface area at a relative pressure of $0.05-0.3$ is most reasonable and has a linear correlation, as shown in Fig. 5(a), which the slopes and intercepts were used to calculate the BET surface area using multi-point measurements (Dogan et al., 2006). Fig. 5(b) shows $\mathrm{SCO}_{2}$ adsorption time $(t)$ versus BET surface area $\left(A_{\mathrm{S}}\right)$ of all shale samples, which were all decreased considerably with the increase of adsorption time. BET surface area decreased with adsorption time and approximately a negative linear relation: $A_{\mathrm{S}} \sim-t$. It should be noticed that the value $A_{\mathrm{S}}$ at $6 \mathrm{~h}$ was abnormal due to the deviation from the fitting line greatly. In this study it was neglected and may deserve further research in future. After $22 \mathrm{~h}$ of $\mathrm{sCO}_{2}$ adsorption, the SSA decreased by up to $36 \%$. 


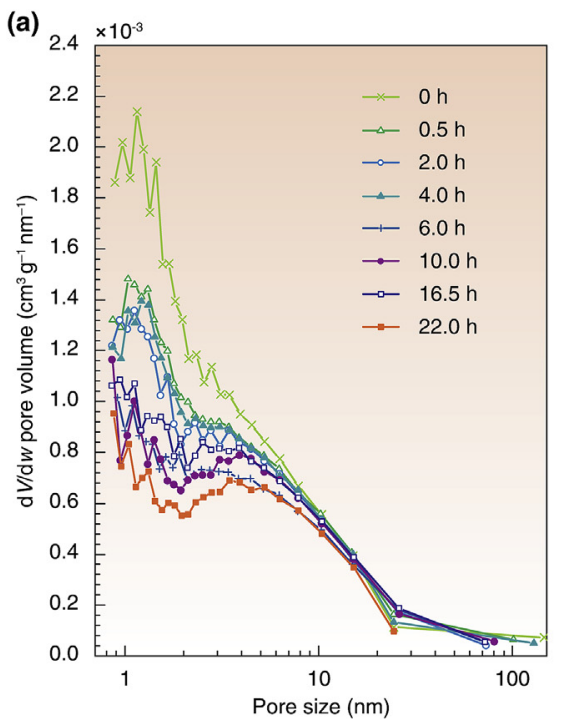

(b)

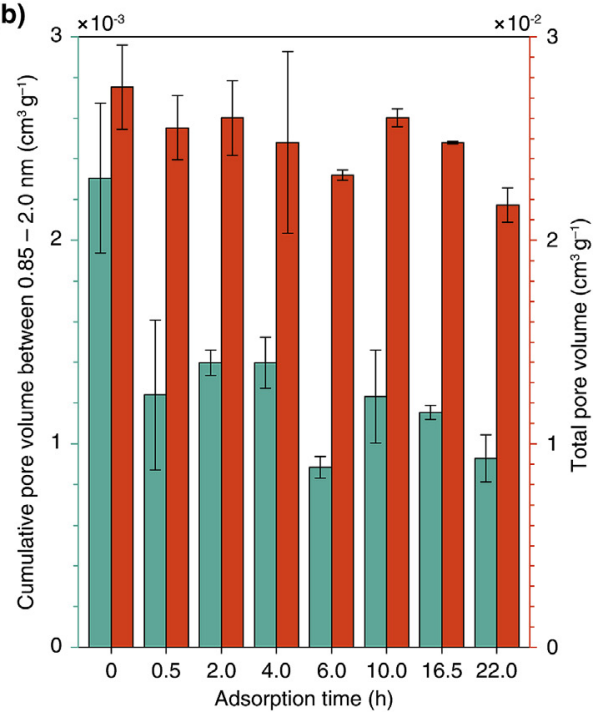

Fig. 6. Statistics of pore size and volume. (a) Pore size distribution of the eight shale samples. As the adsorption time of $\mathrm{sCO}_{2}$ increases, the pore volume decreases, especially in the range of $0.85-2.0 \mathrm{~nm}$. (b) The cumulative pore volume in the range of $0.85-2.0 \mathrm{~nm}$ (turquoise) and the total pore volume (red) vary with the adsorption time. After $22 \mathrm{~h}$ adsorption of $\mathrm{sCO}_{2}$, the former decreased by up to $60 \%$ and the latter decreased by up to $20 \%$. (For interpretation of the references to colour in this figure legend, the reader is referred to the Web version of this article.)

\subsection{Porosity assessment}

The pore size distributions of the eight shale samples were calculated by the Barrett-Joyner-Halenda (BJH) theory (Barrett et al., 1951) from the isotherms. The adsorption branch was chosen for the calculation because the desorption one was unreliable if pore blocking effects occurred (Sing, 1985). In spite of the BJH method has some shortcomings in estimating the pore volume due to some uncertainties arising from the complexities of real pore structures, in this paper it was still recommended herein to provide a general image of the pore structure due to its practicality and simplicity. The $\mathrm{N}_{2}$ adsorption isotherms provide information on size distributions of pores in the range of 0.5-200 nm (Groen et al., 2003; Thommes et al., 2015). Fig. 6(a) shows the distributions of pore volume with respect to pore size. The major pore width was in the range of $0.85-150 \mathrm{~nm}$. With increasing $\mathrm{sCO}_{2}$ adsorption time, the total pore volumes oscillated and the overall trend decreased. As shown in Fig. 6(b), the reduction of the pore volumes, either total or micro, changed with the $\mathrm{sCO}_{2}$ adsorption time. After $22 \mathrm{~h}$, the total pore volume decreased by up to $20 \%$. In particular, the volume of nanopores in the range of $0.85-2.0 \mathrm{~nm}$ declined sharply by up to $60 \%$. The reduction trend of total pore and micropores was consistent.

\subsection{Morphology characterization}

Fig. 7(a) shows a typical shale particle with significant sedimentary rock structural features with abundant pores at the particle surface. The cemented, flaky and pore-rich matters including organics, clays (mainly illite and chlorite), quartz, feldspar, carbonates (calcite and dolomite) and pyrite, etc. formed a dense and layered morphology (Huang and Zhao, 2017). Fig. 7(b) and (c) are a close-up view and EDS map of a primary pore in $7(a)$. The pore was irregular with lanciform calcite covered in the pore wall. The EDS results show that the main elements of the shale were $\mathrm{O}, \mathrm{C}, \mathrm{Mg}, \mathrm{Si}, \mathrm{Al}, \mathrm{Fe}, \mathrm{Ca}$, and $\mathrm{K}$, of which the $\mathrm{C}(30.4 \%)$ and $\mathrm{O}(44.3 \%)$ are the most abundant ones, indicating the organic-rich characteristics of the rock. Fig. 7(d) shows some narrow, slit-shaped open nanopores $(\sim 6 \mathrm{~nm})$ scattered in the organic matters originated from the thermal maturation and conversion (Loucks et al., 2009).

Fig. 7(e) and (f) are the typical region of shale particles before and after $22 \mathrm{~h} \mathrm{sCO}$ adsorption, respectively. The insert in Fig. 7(e) is the EDS spectrum which shows that the content of $\mathrm{C}$ element in this region was very high $(\sim 70 \%)$. Remarkably, there were abundant organic micropores in Fig. $7(\mathrm{e})$, however, most disappeared after the $\mathrm{sCO}_{2}$ adsorption, which was consistent with the decrease in pore volume measured by nitrogen adsorption. In addition, some specific larger mesopores emerged. The morphology of the particle surface got rougher.

\subsection{Composition variations}

Fig. 8(a) and (b) show the XPS survey spectra of the eight shale samples and the calculated composition variations. The presence of $\mathrm{Si}$ $\left(2 \mathrm{p}_{3 / 2}\right)$ was primarily feldspar $\left(\mathrm{NaAlSi}_{3} \mathrm{O}_{8}\right)$, quartz $\left(\mathrm{SiO}_{2}\right)$ and/or metasilicate $\left(\mathrm{SiO}_{3}{ }^{2-}\right.$, e.g. wollastonite). The content of feldspar experienced a decrease $\rightarrow$ increase $\rightarrow$ decrease $\rightarrow$ increase process with increasing the $\mathrm{sCO}_{2}$ adsorption time, which was exactly opposite to the change of quartz (or metasilicate) content, indicating that the two minerals have undergone mutual transformation. The presence of $\mathrm{Mg}(1 \mathrm{~s})$ was primarily magnesia $(\mathrm{MgO})$ and magnesite $\left(\mathrm{MgCO}_{3}\right)$. The trend of the former was similar to that of feldspar, and the latter experienced an increase $\rightarrow$ decrease process. The calcium content in the shale was very low, about $1 \%$. Among them, the content of quicklime $(\mathrm{CaO})$ was almost zero. The calcite $\left(\mathrm{CaCO}_{3}\right)$ was about $\sim 15 \%$. The content changed in a similar trend to magnesite.

\section{Discussion}

From the results stated above, we found that the nanopores had two trends after the $\mathrm{sCO}_{2}$ adsorption: Closing up and new opening. In particular, both the closed and newly opened pores were very small, typically in the range of a few nanometers. The closed nanopores were more than new opened ones. Both the total pore volume and the SSA decreased. And also, minerals varied during the process. This phenomenon can be elucidated from three main aspects, that is, physisorption, associative chemisorption, and dissociative chemisorption, as shown in Fig. 9.

The first and the most important aspect was the physisorption of $\mathrm{CO}_{2}$ in the organic pores. In the shale matrix, the $\mathrm{CO}_{2}$ molecules were most likely to adsorb to the adsorption sites of oil or gas previously occupied in the organic pores. The desorption of hydrocarbons and the adsorption of $\mathrm{CO}_{2}$ will cause a change in the surface energy of the shale, resulting in the swelling phenomenon. Pan and Connell (2007) proposed a theoretical model to describe adsorption-induced coal expansion under adsorption and strain equilibrium, which is somewhat applicable to shale expansion. Their model considered the adsorbent density, porosity, solid elastic modulus, and Poisson's ratio, and combined two effects, that is, swelling due to gas adsorption and compression due to gas pressure. However, the organic matters in sale are 

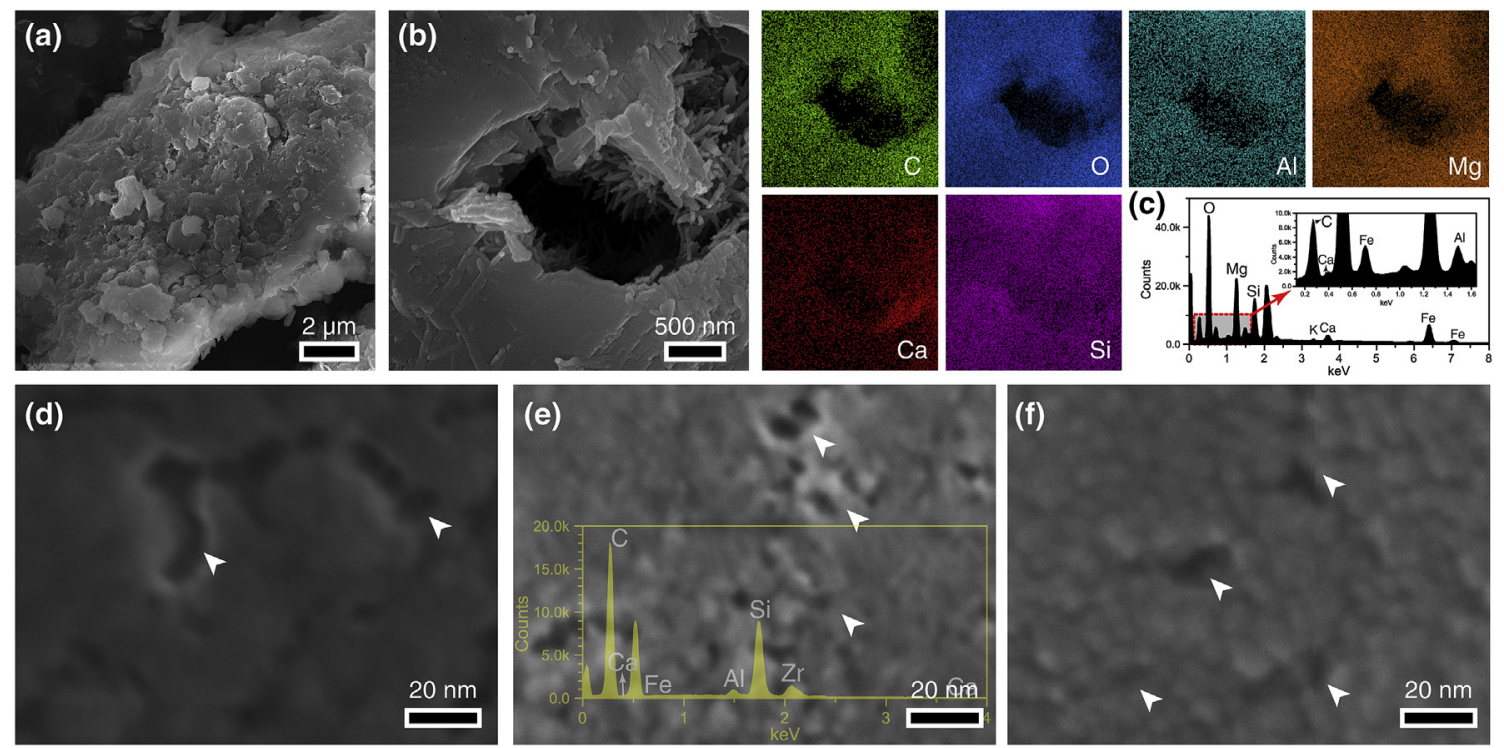

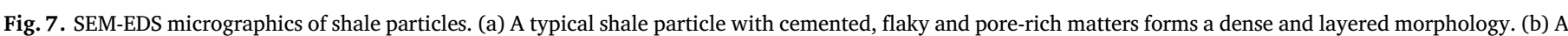

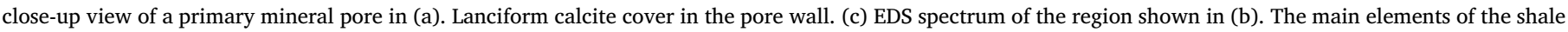

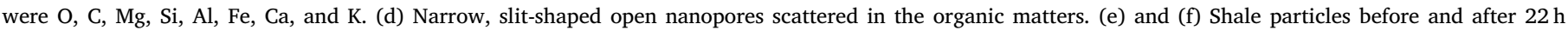
adsorption of $\mathrm{sCO}_{2}$. Many nanopores were blocking, while some were newly opened. The surface of the particle surface became coarser.

more complex and further adsorption effects should be considered. The major organic matter is kerogen (Bousige et al., 2016), a superelastic crosslinked polymer composed of an amorphous porous carbon skeleton having rich nanopores of several $\AA$ to $\mu \mathrm{m}$. During the adsorption process, $\mathrm{CO}_{2}$ diffused into the polymers due to the concentration gradient and was likely to be trapped, as shown in Fig. 9(a) and (b). In this process, the $\mathrm{CO}_{2}$ molecules and the polymers may form hydrogen bonds or undergo a charge transfer, resulting in a decrease in the degree of cross-linking of the macromolecular structure. The phase behavior of polymer-s $\mathrm{CO}_{2}$ system can be described by Panayiotou-Vera equation of state (Panayiotou and Vera, 1982): $\frac{\tilde{P}}{\tilde{T}}=\ln \left(\frac{\tilde{v}}{\tilde{v}-1}\right)+\frac{Z}{2} \ln \left(\frac{\tilde{v}+q / r-1}{\tilde{v}}\right)-\frac{\theta^{2}}{\tilde{T}}$, where $\tilde{P}, \tilde{T}$, vare dimensionless pressure, temperature, and volume respectively; $Z$ is the finite coordination number; $q$ is the effective chain length; $r$ is the lattice sites occupied by the molecule, and $q Z=(Z-2) r+2 ; \theta$ is the surface area fraction of the lattice position occupied by the molecular chain.

The phase change of the kerogen- $\mathrm{SCO}_{2}$ system resulted in a structural rearrangement known as the plasticizing effect and causes the structure to expand and further occupy the pore volume. In this context, the total pore volume, especially the pore volume distributed in the range of micropores, will decrease and may block.

The second factor was the associative chemisorption of $\mathrm{CO}_{2}$ at mineral surfaces or pores. Above the supercritical points with such high pressure and temperature, $\mathrm{CO}_{2}$ and $\mathrm{H}_{2} \mathrm{O}$-albeit little-may react with tiny fragments of minerals of shale to form new products, as shown in Fig. 9 (c). After the $\mathrm{sCO}_{2}$ adsorption, the feldspar experienced a process of decrease-increase-decrease-increase. The possible reaction was:

$\mathrm{NaAlSi}_{3} \mathrm{O}_{8}+\mathrm{CO}_{2}+\mathrm{H}_{2} \mathrm{O} \rightleftharpoons \operatorname{NaAl}\left(\mathrm{CO}_{3}\right)(\mathrm{OH})_{2}+3 \mathrm{SiO}_{2}$

where $\mathrm{NaAlSi}_{3} \mathrm{O}_{8}, \mathrm{NaAl}\left(\mathrm{CO}_{3}\right)(\mathrm{OH})_{2}$, and $\mathrm{SiO}_{2}$ are solids, $\mathrm{CO}_{2}$ is a gas, $\mathrm{H}_{2} \mathrm{O}$ is either the gas or liquid.

Other possible reactions for the associative chemisorption of $\mathrm{sCO}_{2}$ were:

$\mathrm{MgO}+\mathrm{CO}_{2} \rightarrow \mathrm{MgCO}_{3}$ (a)

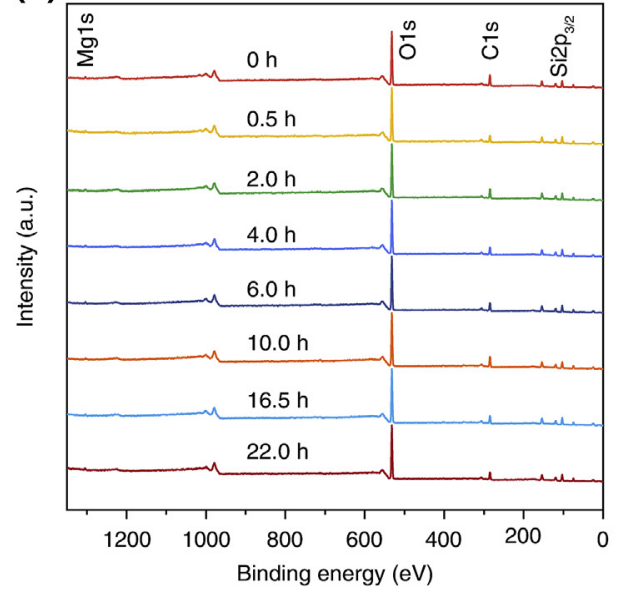

(b)

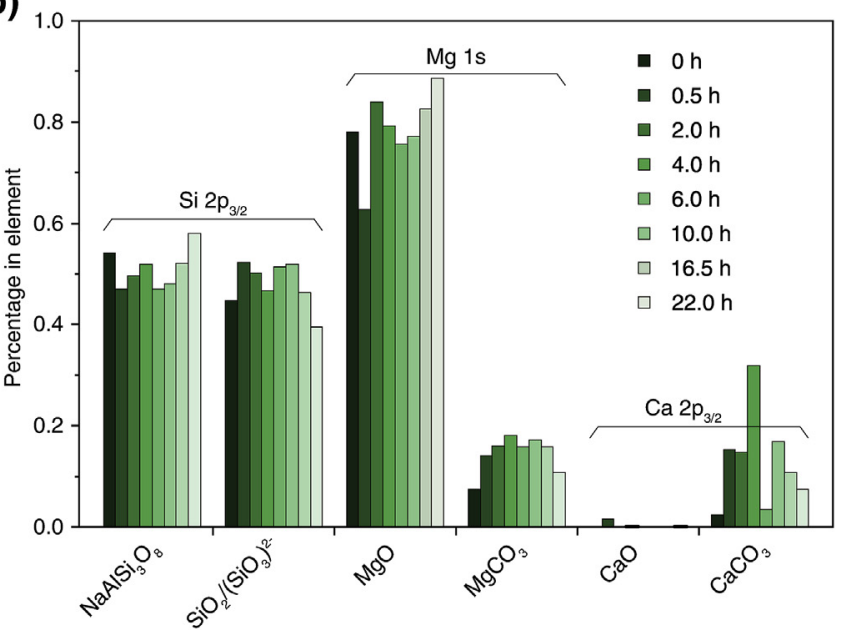

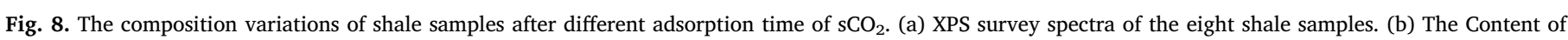

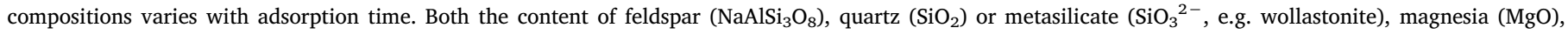
magnesite $\left(\mathrm{MgCO}_{3}\right)$, calcite $\left(\mathrm{CaCO}_{3}\right)$ experienced considerable changes during adsorption of $\mathrm{sCO}_{2}$. 


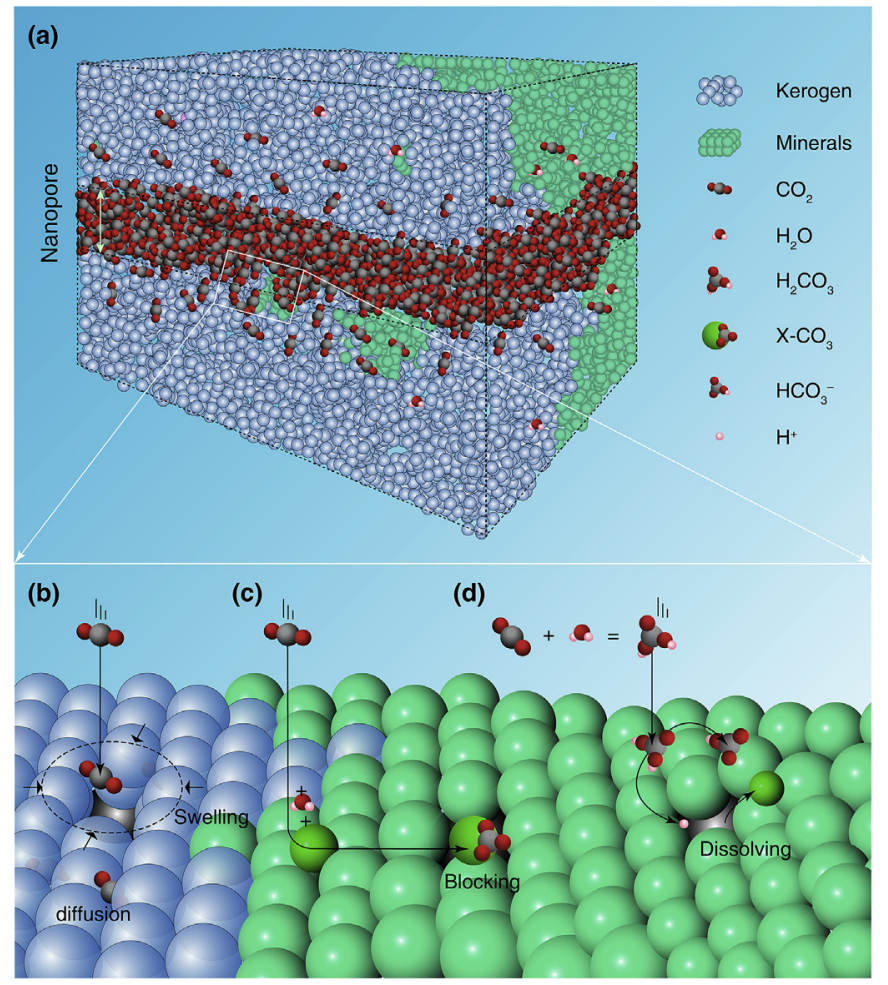

Fig. 9. Physisorption, associative chemisorption, and dissociative chemisorption of $\mathrm{sCO}_{2}$ in shale matrix. (a) Illustration of a nanopore of kerogen and minerals in $\mathrm{sCO}_{2}$ environment. (b) Physisorption of $\mathrm{CO}_{2}$. The molecule adsorbs to the adsorption sites of oil and gas, as well as diffused in the organic polymers, resulting in the swelling phenomenon and blocking the nanopores. (c) Associative chemisorption of $\mathrm{CO}_{2} \cdot \mathrm{CO}_{2}$ and $\mathrm{H}_{2} \mathrm{O}$ may react with tiny fragments of minerals in shale to form new products, which may also block the nanopore and make the surface rougher. (d) Dissociative chemisorption. $\mathrm{CO}_{2}$ bonds with water and then dissociates $\mathrm{H}^{+}$on the shale surface, which dissolves some certain minerals in the rock and creates new nanopores.

$$
\begin{aligned}
& \mathrm{Mg}(\mathrm{OH})_{2}+\mathrm{CO}_{2} \rightarrow \mathrm{MgCO}_{3}+\mathrm{H}_{2} \mathrm{O} \\
& \mathrm{Ca}(\mathrm{OH})_{2}+\mathrm{CO}_{2} \rightarrow \mathrm{CaCO}_{3}+\mathrm{H}_{2} \mathrm{O} .
\end{aligned}
$$

All of these reactions were a complex process of interaction between multiple fluids and solids. Although they may be reversible, it had a major impact on the migration of minerals, pore presence, and elemental storage state in shale. As shown in Fig. 9(c), the new products will cover the surface of the rock and the walls of the pores, or expand the minerals fragments, imposing a geochemical and morphological changes to the rock. As a result, the pore may block, and the pore volume decrease.

The last aspect came to the dissociative chemisorption of $\mathrm{CO}_{2}$ at mineral surfaces or pores. When the $\mathrm{sCO}_{2}$ was injected, $\mathrm{CO}_{2}$ bonded with underground water-again, albeit little-and produced carbonic acid $\left(\mathrm{H}_{2} \mathrm{CO}_{3}\right): \mathrm{CO}_{2}+\mathrm{H}_{2} \mathrm{O} \leftrightharpoons \mathrm{H}_{2} \mathrm{CO}_{3}$. As the carbonic acid adsorbed to the shale surface, it dissociated into $\mathrm{H}^{+}$and $\mathrm{HCO}_{3}{ }^{-}$. The $\mathrm{pH}$ increased with increasing temperature and was always weakly acidic. In the presence of $\mathrm{H}^{+}$, some mineral components in the rock will be dissolved and corroded, as shown in Fig. 9(d). Possible reactions were:

$\mathrm{KAlSi}_{3} \mathrm{O}_{8}+4 \mathrm{H}_{2} \mathrm{O}+4 \mathrm{H}^{+} \rightarrow \mathrm{K}^{+}+\mathrm{Al}^{3+}+3 \mathrm{H}_{4} \mathrm{SiO}_{4}$

and

$\mathrm{NaAlSi}_{3} \mathrm{O}_{8}+4 \mathrm{H}_{2} \mathrm{O}+4 \mathrm{H}^{+} \rightarrow \mathrm{Na}^{+}+\mathrm{Al}^{3+}+3 \mathrm{H}_{4} \mathrm{SiO}_{4}$

where $\mathrm{NaAlSi}_{3} \mathrm{O}_{8}$ and $\mathrm{KAlSi}_{3} \mathrm{O}_{8}$ are the major compositions of feldspar. As the reaction proceeded, for one thing it consumed consumes a large amount of $\mathrm{H}^{+}$, and made the balance of carbonic acid production to the right. For another consumed large amounts of $\mathrm{H}_{2} \mathrm{O}$, indicating that the effect of dissociative chemisorption was much weaker than the first two adsorptions.

The dissolution of minerals had two main effects on shale: Corrode the mineral to create pores, and reprecipitate on the shale surface with secondary minerals. For the former, as the $\mathrm{CO}_{2}$ was continuously adsorbed, the pore structure of the rock changed, thereby opened some of the original closed or semi-closed pores in the process, as shown in Fig. 7(f) and the right schematic of Fig. 9(d). For the later, the dissolution of minerals in acidic solution was incongruent, in which part of the ions were dissolved into the solution and the others were converted into secondary minerals. Obviously, the products $\mathrm{K}^{+}, \mathrm{Al}^{3+}$ and $\mathrm{Na}^{+}$ will serve as the ion source for the new minerals. As discussed above with regard to associative chemisorption, the secondary minerals will cover the surface of the rock and the walls of the pores, resulting in the redistribution of minerals, pore presence, and elemental storage state in shale. Remarkably, they may block pores. Combining these two effects, the pore volume may either increase or decrease, and the surface will get rougher in the process. This may explain why the pore volume oscillated with the $\mathrm{sCO}_{2}$ adsorption time.

\section{Conclusions}

In summary, we first discover the adsorption-induced pore blocking phenomenon in nanoporous shale due to interactions with $\mathrm{sCO}_{2}$, and show that the total pore volume of shale drops sharply by up to $20 \%$ and SSA by up to $36 \%$ after $\mathrm{sCO}_{2}$ adsorption. In particular, the volume of nanopores in the range of $0.85-2.0 \mathrm{~nm}$ declined sharply by up to $60 \%$. These significant reductions are due to the three major geochemical reactions of $\mathrm{sCO}_{2}$ molecules with the rock, namely physisorption, associative chemisorption and dissociative chemisorption. The physisorption is that the $\mathrm{CO}_{2}$ molecules adsorb to the organic pores and diffuse in the cross-linked polymers. It is responsible for the swelling phenomenon that causes the structure to expand and further occupy the pore volume. The association chemisorption involves in the reactions of minerals with water and $\mathrm{CO}_{2}$. The new mineral products will impact on the mineral migration, pore presence, and elemental storage state in shale. The dissociative chemisorption is that $\mathrm{CO}_{2}$ molecules bond with underground water to form carbonic acid $\left(\mathrm{H}_{2} \mathrm{CO}_{3}\right)$, and then dissociate into $\mathrm{H}^{+}$and $\mathrm{HCO}_{3}{ }^{-}$on the shale surface. In the presence of $\mathrm{H}^{+}$, some mineral components in the rock will be dissolved and corroded, and thereby open some of the original closed or semiclosed pores. The blocking of nanopores may also happen for there are secondary minerals generated during the dissolution. All of these changes, either physical or chemical, voluminal or mechanical, will reform the shale, its pore structure and size distribution, the surface roughness, resulting in the significant decrease of both total pore volume and SSA. These changes will also adversely affect the hydrocarbon production and $\mathrm{CO}_{2}$ storage, thus forming a complex system that mutually restricts and influences each other. The results help us to assess the efficiency of hydrocarbon production using $\mathrm{CO}_{2}$-fracking, and as well the $\mathrm{CO}_{2}$ storage potential in shale formations.

\section{Acknowledgments}

This work was jointly supported by the National Natural Science Foundation of China (NSFC, Grant No. 11702299, 11872363, 51861145314), the Chinese Academy of Sciences (CAS) Interdisciplinary Innovation Team Project, the CAS Key Research Program of Frontier Sciences (Grant No. QYZDJ-SSW-JSC019), and the CAS Strategic Priority Research Program (Grant No. XDB22040401).

\section{Appendix A. Supplementary data}

Supplementary data to this article can be found online at https:// doi.org/10.1016/j.petrol.2019.03.018. 


\section{References}

Barrett, E.P., Joyner, L.G., Halenda, P.P., 1951. The determination of pore volume and area distributions in porous substances. I. Computations from nitrogen isotherms. J. Amer. Chem. Soc. 73 (1), 373-380.

Bousige, C., et al., 2016. Realistic molecular model of kerogen's nanostructure. Nat. Mater. 15 (5), 576.

Brunauer, S., Emmett, P.H., Teller, E., 1938. Adsorption of gases in multimolecular layers. J. Amer. Chem. Soc. 60 (2), 309-319.

Burnham, A.K., Pomerantz, A.E., Gelin, F., 2018. Oil, bitumen, and other confusing concepts: what do lab experiments really tell us? AAPG Bull. 102 (4), 653-669.

Busch, A., et al., 2016. On sorption and swelling of $\mathrm{CO}_{2}$ in clays. Geomech. Geophys. Geoenerg. Geo-resour. 2 (2), 111-130.

Chen, J., Wang, F., Liu, H., Wu, H., 2017. Molecular mechanism of adsorption/desorption hysteresis: dynamics of shale gas in nanopores. SCI. China Phys. Mech. 60 (1), 014611.

Clarkson, C.R., et al., 2013. Pore structure characterization of North American shale gas reservoirs using USANS/SANS, gas adsorption, and mercury intrusion. Fuel 103, 606-616.

Dogan, A.U., et al., 2006. Baseline studies of the clay minerals society source clays: specific surface area by the Brunauer Emmett Teller (BET) method. Clay. Clay Miner. 54 (1), 62-66.

Edwards, R.W., Celia, M.A., Bandilla, K.W., Doster, F., Kanno, C.M., 2015. A model to estimate carbon dioxide injectivity and storage capacity for geological sequestration in shale gas wells. Environ. Sci. Technol. 49 (15), 9222-9229.

Ellsworth, W.L., 2013. Injection-induced earthquakes. Science 341 (6142), 1225942.

Falk, K., Coasne, B., Pellenq, R., Ulm, F.-J., Bocquet, L., 2015. Subcontinuum mass transport of condensed hydrocarbons in nanoporous media. Nat. Commun. 6, 6949.

Farajzadeh, R., Salimi, H., Zitha, P.L.J., Bruining, H., 2007. Numerical simulation of density-driven natural convection in porous media with application for $\mathrm{CO} 2$ injection projects. Int. J. Heat Mass Tran. 50 (25-26), 5054-5064.

Godec, M., Koperna, G., Petrusak, R., Oudinot, A., 2013. Potential for enhanced gas recovery and $\mathrm{CO}_{2}$ storage in the Marcellus Shale in the Eastern United States. Int. J. Coal Geol. 118, 95-104.

Groen, J.C., Peffer, L.A.A., Perez-Ramirez, J., 2003. Pore size determination in modified micro- and mesoporous materials. Pitfalls and limitations in gas adsorption data analysis. Micropor. Mesopor. Mat. 60 (1-3), 1-17.

Hanrahan, J.P., et al., 2004. Pore expansion in mesoporous silicas using supercritical carbon dioxide. Chem. Mater. 16 (3), 424-427.

Howarth, R.W., Ingraffea, A., Engelder, T., 2011. Natural gas: should fracking stop? Nature 477 (7364), 271.

Huang, X., Zhao, Y.-P., 2017. Characterization of pore structure, gas adsorption, and spontaneous imbibition in shale gas reservoirs. J. Petrol. Sci. Eng. 159, 197-204.

Hughes, J.D., 2013. Energy: a reality check on the shale revolution. Nature 494 (7437), 307-308.

Jackson, R.B., et al., 2013. Increased stray gas abundance in a subset of drinking water wells near Marcellus shale gas extraction. Proc. Natl. Acad. Sci. U. S. A. 110 (28), $11250-11255$.

Jiang, Y., Luo, Y., Lu, Y., Qin, C., Liu, H., 2016. Effects of supercritical $\mathrm{CO}_{2}$ treatment time, pressure, and temperature on microstructure of shale. Energy 97, 173-181.

Kang, S.M., Fathi, E., Ambrose, R.J., Akkutlu, I.Y., Sigal, R.F., 2011. Carbon dioxide storage capacity of organic-rich shales. SPE J. 16 (04), 842-855.

Kerr, R.A., 2010. Natural gas from shale bursts onto the scene. Science 328, 1624-1626.

Lee, T., Bocquet, L., Coasne, B., 2016. Activated desorption at heterogeneous interfaces and long-time kinetics of hydrocarbon recovery from nanoporous media. Nat. Commun. 7, 11890.

Lin, K., Yuan, Q., Zhao, Y.P., Cheng, C., 2016. Which is the most efficient candidate for the recovery of confined methane: water, carbon dioxide or nitrogen? Extreme Mech. Lett. 9, 127-138.

Liu, K., et al., 2018. Multifractal analysis of gas adsorption isotherms for pore structure characterization of the Bakken Shale. Fuel 219, 296-311.

Liu, K., et al., 2019. Nanopore structure comparison between shale oil and shale gas: Examples from the Bakken and Longmaxi Formations. Petrol. Sci. 16, 77-93.

Loucks, R.G., Reed, R.M., Ruppel, S.C., Jarvie, D.M., 2009. Morphology, genesis, and distribution of nanometer-scale pores in siliceous mudstones of the Mississippian Barnett shale. J. Sediment. Res. 79 (11-12), 848-861.

Lu, Y., et al., 2016. Swelling of shale in supercritical carbon dioxide. J. Nat. Gas Sci. Eng. 30, 268-275.

Lyu, Q., et al., 2018. Experimental investigation on the mechanical properties of a lowclay shale with different adsorption times in sub-/super-critical $\mathrm{CO}_{2}$. Energy 147 , 1288-1298.

Middleton, R.S., et al., 2015. Shale gas and non-aqueous fracturing fluids: opportunities and challenges for supercritical $\mathrm{CO}_{2}$. Appl. Energ. 147, 500-509.

Monteiro, P.J., Rycroft, C.H., Barenblatt, G.I., 2012. A mathematical model of fluid and gas flow in nanoporous media. Proc. Natl. Acad. Sci. U. S. A. 109 (50), 20309-20313.

Niu, Q., et al., 2017. The adsorption-swelling and permeability characteristics of natural and reconstituted anthracite coals. Energy 141, 2206-2217.

Osborn, S.G., Vengosh, A., Warner, N.R., Jackson, R.B., 2011. Methane contamination of drinking water accompanying gas-well drilling and hydraulic fracturing. Proc. Natl. Acad. Sci. U. S. A. 108 (20), 8172-8176.

Pan, Z., Connell, L.D., 2007. A theoretical model for gas adsorption-induced coal swelling. Int. J. Coal Geol. 69 (4), 243-252.

Panayiotou, C., Vera, J., 1982. Statistical thermodynamics of $r$-mer fluids and their mixtures. Polym. J. 14 (9), 681.

Pekot, L., Reeves, S., 2002. Modeling coal matrix shrinkage and differential swelling with $\mathrm{CO}_{2}$ injection for enhanced coalbed methane recovery and carbon sequestration applications. Adv. Res. Int. Incorporated.

Perera, M., Ranjith, P., Viete, D., 2013. Effects of gaseous and super-critical carbon dioxide saturation on the mechanical properties of bituminous coal from the Southern Sydney Basin. Appl. Energ. 110, 73-81.

Phan, A., Cole, D.R., Weiß, R.G., Dzubiella, J., Striolo, A., 2016. Confined water determines transport properties of guest molecules in narrow pores. ACS Nano 10 (8), 7646-7656.

Pomerantz, A.E., 2015. Method to characterize shales at high spatial resolution. Google Patents, US Patent 9 (128), 210.

Shen, W., Zhao, Y.-P., 2017. Quasi-static crack growth under symmetrical loads in hydraulic fracturing. J. Appl. Mech.-T. ASME 84 (8), 081009.

Sing, K.S., 1985. Reporting physisorption data for gas/solid systems with special reference to the determination of surface area and porosity (Recommendations 1984). Pure Appl. Chem. 57 (4), 603-619.

Stringfellow, W.T., Domen, J.K., Camarillo, M.K., Sandelin, W.L., Borglin, S., 2014. Physical, chemical, and biological characteristics of compounds used in hydraulic fracturing. J. Hazard. Mater. 275, 37-54.

Thommes, M., et al., 2015. Physisorption of gases, with special reference to the evaluation of surface area and pore size distribution (IUPAC Technical Report). Pure Appl. Chem. 87 (9-10), 1051-1069.

Vengosh, A., Jackson, R.B., Warner, N., Darrah, T.H., Kondash, A., 2014. A critical review of the risks to water resources from unconventional shale gas development and hydraulic fracturing in the United States. Environ. Sci. Technol. 48 (15), 8334-8348.

Vidic, R.D., Brantley, S.L., Vandenbossche, J.M., Yoxtheimer, D., Abad, J.D., 2013. Impact of shale gas development on regional water quality. Science 340 (6134), 1235009.

Wang, J., Ju, Y., Gao, F., Peng, Y., Gao, Y., 2015. Effect of $\mathrm{CO}_{2}$ sorption-induced anisotropic swelling on caprock sealing efficiency. J. Clean. Prod. 103, 685-695.

Wood, J.M., Sanei, H., 2016. Secondary migration and leakage of methane from a major tight-gas system. Nat. Commun. 7, 13614.

Wu, H.A., Chen, J., Liu, H., 2015. Molecular dynamics simulations about adsorption and displacement of methane in carbon nanochannels. J. Phys. Chem. C 119 (24), 13652-13657.

Yang, J., Hatcherian, J., Hackley, P.C., Pomerantz, A.E., 2017. Nanoscale geochemical and geomechanical characterization of organic matter in shale. Nat. Commun. 8 (1), 2179.

Yu, H., Fan, J., Chen, J., Zhu, Y., Wu, H., 2018. Pressure-dependent transport characteristic of methane gas in slit nanopores. Int. J. Heat Mass Tran. 123, 657-667.

Zhong, J., et al., 2016. Condensation in one-dimensional dead-end nanochannels. ACS Nano 11 (1), 304-313.

Zhou, J., et al., 2017. Pore structural characterization of shales treated by sub-critical and supercritical $\mathrm{CO}_{2}$ exposure. J. Nanosci. Nanotechno. 17 (9), 6603-6613. 